\title{
Descriptive analysis of mycological examination of patients with onychomycosis treated in private practice*
}

\author{
John Verrinder Veasey ${ }^{1}$ \\ Clarisse Zaitz ${ }^{1}$
}

\author{
Flávio Nappi ${ }^{1}$ \\ Laura Hitomi Muramatu ${ }^{1}$
}

DOI: http:/ / dx.doi.org/10.1590/abd1806-4841.20174874

\begin{abstract}
This is a retrospective study of 160 patients treated in private practice in São Paulo from March 2003 to March 2015. We analyzed 171 results of direct mycological examinations and fungal cultures from nail scrapings. The agreement between direct mycological examination results and fungal culture was satisfactory, consistent with the literature (kappa 0.603). The main agent identified was Trichophyton rubrum (51\%). We observed an isolation rate of non-dermatophyte filamentous fungi superior to the literature (34\%). Determining the agent is key to defining the appropriate onychomycosis treatment, and knowing the epidemiology of patients treated in private practice helps the dermatologist who works in this context.

Keywords: Culture; Culture mediums; Data analysis; Doctors' office; Epidemiology; Fungal structures; Fungi; Opportunistic infections; Mycoses; Onychomycosis; Private practice; Tinea
\end{abstract}

Onychomycosis is a frequent cause for consultation in dermatological practice, both in public and private and services. ${ }^{1,2}$ The identification of the etiologic agent is critical to define its treatment. ${ }^{3,4}$ In Brazil research mainly describes the epidemiology in public practice settings, with rare analysis of samples collected exclusively from patients treated in private practice..$^{5-8}$

We conducted a retrospective study in a dermatological private clinic in São Paulo. Two dermatologists with extensive experience in dermatomycoses work in this private clinic, both in diagnosis and treatment. We analyzed all medical records of patients admitted with suspected onychomycosis from March 2003 to March 2015. In all cases, patients suspected of onychomycosis underwent collection of subungueal samples (no cases of superficial onychomycosis were reported). The sample was then sent to a laboratory of clinical analysis with a specialized mycology sector and an experienced biomedical. In this laboratory, part of the sample was clarified in $\mathrm{KOH} 10 \%$ with dimethyl sulfoxide solution and analyzed by optical microscopy to identify fungal structures (direct mycological examination - DME). The rest of the sample was routinely used for cultures in the laboratory for each sample collection carried out: inoculation in two tubes containing Sabouraud dextrose agar (Difco, USA) and two containing Mycosel (Difco, USA). The identification of agents was made by macro cultivation when features were typical. In doubtful or suspected cases of non-dermatophytes filamentous fungi (NDFF), micro cultivation in potato dextrose agar was systematically performed with subsequent microscopic morphological analysis. Observation time of colonies in macro cultivation and micro cultivation was one month with incubation at room temperature $\left(25^{\circ} \mathrm{C}\right)$.

Agents were considered as dermatophytes when DME revealed septate hyphae and/or arthroconidia for filamentous fungi and culture revealed a dermatophyte fungus. However, they were considered as Candida when DME revealed pseudo-hyphae and blastoconidia and the culture revealed Candida spp. The agents were considered as NDFF after three collections made with at least a week between each other; in all the samples, DME should present septate hyphae and/or arthroconidia for filamentous fungi and cultures, the exclusive growth of the same NDFF.

Of patients with clinical suspicion of onychomycosis, $63 \%$ (109) had positive DME results (Table 1). This DME positivity rate was higher than those described by Souza et al. (53\%), Azambuja et al. ${ }^{5}(58 \%)$, and Siqueira et al. $(11.1 \%){ }^{6}$

The degree of agreement between DME and cultivation found in our study was moderate with kappa 0.603 (CI 0.4654 -

Received on 24.06 .2015

Approved by the Advisory Board and accepted for publication on 16.02.2016

* Work performed at Private Practice and Mycology Laboratory of the Dermatology Clinic at Santa Casa de Misericórdia de São Paulo - São Paulo (SP), Brazil. Financial Support: None.

Conflict of Interest: None.

Irmandade da Santa Casa de Misericórdia de São Paulo - São Paulo (SP), Brazil.

C 2017 by Anais Brasileiros de Dermatologia 
TABLE 1: Mycological examination of patients with suspected onychomycosis in private practice in São Paulo (2003 - 2015)

\begin{tabular}{lllll}
\hline & & $\begin{array}{c}\text { Culture } \\
\text { Positive }\end{array}$ & Negative & Total \\
\hline $\begin{array}{l}\text { Direct } \\
\text { mycological } \\
\text { examination }\end{array}$ & Positive & 74 & 35 & $109(63 \%)$ \\
Total & & 0 & 62 & $62(37 \%)$ \\
\hline
\end{tabular}

0.714) - calculated with the aid of the software EpiInfo version 7 -, higher than that found by Azambuja et. $\mathrm{al}^{5}(\mathrm{kappa}=0.385)$ and statistically compatible with the work of Souza et al. ${ }^{9}(\mathrm{kappa}=0.54)$, and Zanardi et al. ${ }^{10}$ (kappa $=0.63$ ). A higher DME positivity when cultures are compared - as seen in this study and in others - is expected by the fact that the positivity of the test depends only on the observation of parasitic structures. In cultures, however, not only the presence of the agent, but also its viability and correct cultivation methods are required to confirm the diagnosis.

Another interesting fact concerns the degree and tendency to disagreement between DME and culture, which were assessed by the McNemar test with statistical significance $(33,029, \mathrm{p}=0.0001)$. In our work, we found no negative mycological examination with positive culture, and we found 35 cases of positive direct mycological examination with negative cultures. This data reinforces the fact that, as previously mentioned, culture underestimates cases of onychomycosis when compared to DME. Therefore, culture should be used as a complementary method to EMD for the diagnosis of onychomycosis. Its main objective is to guide the choice of the therapeutic approach since onychomycosis agents present different sensitivity profiles to the antifungals available.,

Of the positive cultures, the main agent identified was Trichophyton rubrum (37 cases - 51\%). Four patients showed growth in Trichophyton mentagrophytes culture (5\%) and, in eight cases (11\%), Candida spp. yeasts were isolated. 24 cases $(33 \%)$ revealed NDFFs, among them: 8 (11\%) cases of Fusarium spp.; 11 (16\%) of Neoscytalidium spp. (7 cases of the hyalinum variety and 4 cases of the dimidiatum variety); 3 (4\%) of Penicillium spp.; 1 (1\%) case of Paecilomyces spp.; and $1(1 \%)$ case of Curvularia spp. (Graph 1$)$.

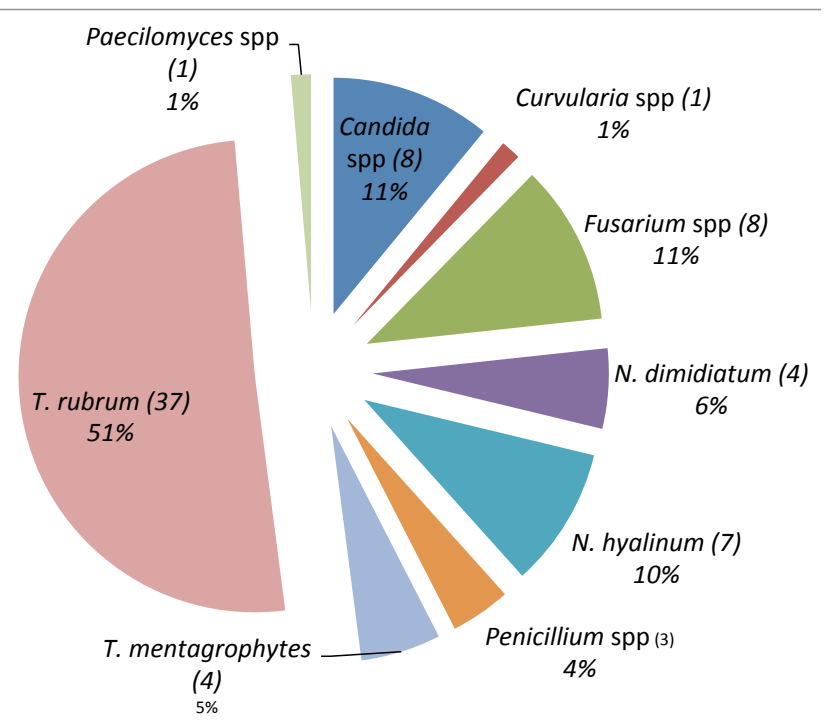

Graph 1: Identification of isolated fungi from nails in patients with onychomycosis

Gupta et al. ${ }^{3}$ performed a meta-analysis study on NDFF causative of onychomycosis, revealing a frequency of $10 \%$ in all cases. Our study showed an extremely high frequency (34\%) as expected because of the biased sample obtained in a reference clinic for the treatment of difficult management onychomycosis, which increases the likelihood of infections by NDFF, known to be more resistant to conventional treatment.

Causative agent identification is essential for the proper treatment of onychomycosis..$^{3,411}$ While the most used systemic drug for dermatophytes is terbinafine, cases of onychomycosis caused by NDFFs generally require the association of other antifungals such as itraconazole. ${ }^{3,4}$

Despite the bias presented by the high incidence of NDFF in the identified fungi, this survey is important for describing the results of the material collected exclusively in private practice. Dermatologists should be familiar with these results since onychomycosis is a frequent complaint by patients. Trichophyton rubrum remains the main causative agent identified. However, in cases of resistance to conventional treatment for dermatophytes, physicians should consider the possibility of onychomycosis caused by NDFF.] 


\section{REFERENCES}

1. Lopes LRS, Kundman D, Duarte IAG. Avaliação da frequência de dermatoses no serviço ambulatorial de dermatologia. An Bras Dermatol. 2010;85:264-6.

2. Sociedade Brasileira de Dermatologia. Perfil nosológico das consultas dermatológicas no Brasil. An Bras Dermatol. 2006;81:549-58.

3. Gupta AK, Drummond-Main C, Cooper EA, Brintnell W, Piraccini BM, Tosti A. Systematic review of nondermatophyte mold onychomycosis: Diagnosis, clinical types, epidemiology, and treatment. J Am Acad Dermatol. 2012;66:494502.

4. Baran R1, Sigurgeirsson B, de Berker D, Kaufmann R, Lecha M, Faergemann $J$, et al. A multicentre, randomized, controlled study of the efficacy, safety and cost-effectiveness of a combination therapy with amorolfine nail lacquer and oral terbinafine compared with oral terbinafine alone for the treatment of onychomycosis with matrix involvement. Br J Dermatol. 2007;157:149-57.

5. Azambuja CVA, Pimmel LA, Klafke GB, Xavier MO Onicomicoses: investigação clínica e micológica e testes de suscetibilidade in vitro dos isolados de Trichophyton rubrum. An Bras Dermatol. 2014;89:581-6.

6. Siqueira ER, Ferreira, JC, Maffei, CML, Candido, RC. Occurrence of dermatophyte, in nails, feet and hands of university students. Rev Soc Bras Med Trop. 2006;39:269-71

7. Di Chiacchio N, Madeira CL, Humaire CR, Silva CS, Fernandes LHG, Reis AL. Micoses superficiais no Hospital do Servidor Público Municipal de São Paulo no período entre 2005 e 2011. An Bras Dermatol. 2014;89:67-71.

8. Araújo AJG, Bastos OMP, Souza MAJ, Oliveira JC. Ocorrência de onicomicoses em pacientes atendidos em consultórios dermatológicos da cidade do Rio de Janeiro, Brasil. An Bras Dermatol. 2003;78:299-308.

9. Souza PR, Vettorato G, Pinto GM, Duquia RP, Amaro TG, Almeira Junior HL, et al. Concordance between direct microscopy and fungical culture for the diagnostic of feet's onychomycosis. An Bras Dermatol. 2012;87:157-9.

10. Zanardi D, Nunes DH, Pacheco AS, Tubone MQ, Souza Filho JJ. Avaliação dos métodos diagnósticos para onicomicose. An Bras Dermatol. 2008;83:119-24.

11. Uptodate.com [Internet]. Onychomycosis [cited 2015 Jun 24]. Available from: $\quad$ http://www.uptodate.com/contents/onychomycosis? source $=$ search result\&search $=$ onicomicose \&selectedTitle $=1 \% 7 \mathrm{E} 23$
MAILING ADDRESS:

John Verrinder Veasey

Private office

Rua Padre João Manuel, 1212 conjunto 113

01411000 São Paulo, SP - Brazil

Mycology Laboratory:

Rua Dr. Cesario Mota Jr, 112

01221100 São Paulo, SP - Brazil

E-mail: johnveasey@uol.com.br

How to cite this article: Veasey JV, Nappi F, Zaitz C, Muramatu LH. Descriptive analysis of mycological examination of patients with onychomycosis treated in private practice. An Bras Dermatol. 2017;92(1):134-6. 